\title{
Decompressive Hemicraniectomy for Stroke in Older Adults: A Review
}

\author{
Faith C. Robertson ${ }^{1,2}$, Hormuzdiyar H. Dasenbrock ${ }^{1,2,3}$, William B. Gormley ${ }^{1,2,3}$ \\ ${ }^{\prime}$ Harvard Medical School, Boston, Massachusetts, United States of America \\ ${ }^{2}$ Cushing Neurosurgical Outcomes Center, Brigham and Women's Hospital, Boston, Massachusetts, United States of America \\ ${ }^{3}$ Department of Neurological Surgery, Brigham and Women's Hospital, Boston, Massachusetts, United States of America
}

Article Info

\section{Article Notes}

Received: November 30, 2016

Accepted: January 18, 2017

\section{*Correspondence:}

William B. Gormley M.D., M.P.H, M.B.A., Department of Neurosurgery

Brigham and Women's Hospital and Harvard Medical School,

75 Francis Street, Boston, Massachusetts 02115

Telephone: (617) 734-8342

Fax: (617) $734-8342$

E-mail: wgormley@partners.org

( 2016 Gormley WB. This article is distributed under the terms of the Creative Commons Attribution 4.0 International License

\section{Keywords}

Age

Cerebral infarction

Decompressive craniectomy

Hemicraniectomy

Ischemic stroke

Middle cerebral artery

\section{ABSTRACT}

Malignant cerebral edema is a potential consequence of large territory cerebral infarction, as the resultant elevation in intracranial pressure may progress to transtentorial herniation, brainstem compression, and death. In appropriate patients, decompressive hemicraniectomy (DHC) reduces mortality without increasing the risk of severe disability. However, as the foundational DHC randomized, controlled trials excluded patients greater than 60 years of age, the appropriateness of DHC in older adults remains controversial. Recent clinical trials among elderly participants, including DESTINY II, reported that DHC reduces mortality, but may leave patients with substantial morbidity. Nationwide analyses have demonstrated generalizability of such data. However, what constitutes an acceptable outcome - the perspective on quality of life after survival with substantial disability - varies between clinicians, patients, and caregivers. Consequently, quality of life measures are being increasingly incorporated into stroke research. This review summarizes the impact of DHC in space-occupying cerebral infarction, and the influence of patient age on postoperative survival, functional capacity, and quality of life-all key factors in the clinical decision process. Ultimately, these data underscore the inherent complexity in balancing scientific evidence, clinical expertise, and patient and family preference when pursuing hemicraniectomy among the elderly.

\section{Abbreviations}

BI: Barthel Index; DHC: decompressive hemicraniectomy; EQ-5D: European Quality of Life Scale; mRS: modified Rankin Scale; QoL: quality of life; RCT: randomized controlled trial.

\section{Introduction}

Acute ischemic stroke disproportionally affects older individuals ${ }^{47}$ and as benefits of procedural interventions for stroke can vary by age $\mathrm{e}^{20}$ it is imperative to understand how medical and surgical expectations change for older patients. In large vessel acute ischemic stroke, the evolution of spaceoccupying cerebral infarctions to malignant cerebral edema is a major cause of neurologic morbidity and mortality, as increases in intracranial pressure progress to transtentorial herniation and brainstem compression ${ }^{19}$. The benefit of surgical intervention was demonstrated in the last decade when three European randomized trials were conducted simultaneously to compare decompressive hemicraniectomy (DHC) to conservative management ${ }^{17,21,26,37}$. However, these trials excluded patients over 60 years of age, leaving to question the appropriateness of DHC for elderly patients.

As DHC utilization continues to increase in the setting of acute ischemic stroke ${ }^{1,42}$ realizing the impact of patient age on DHC outcomes is necessary, particularly in the setting of an increasing life expectancy for people with multiple comorbidities and stroke risk factors ${ }^{12}$. This review involved a 
literature research of PubMed to identify relevant studies published before November 2016. The search strategy included the following $\mathrm{MeSH}$ terms and keywords: ("hemicraniectomy" OR "decompressive surgery" OR "DHC") AND ("age" OR "elderly" OR "older patients") AND "stroke". Titles and abstracts were reviewed to identify potentially relevant studies. We summarize the utility of DHC, the current understanding of how age (particularly age greater than 60 years) influences postoperative survival, functional capacity, and quality of life, and how that data impacts the complex decision analysis in the clinical setting.

\section{Decompressive Hemicraniectomy for Stroke}

Surgical decompression became a prominent treatment option for acute ischemic stroke in the $1990 \mathrm{~s}^{7,19,32}$. Multiple observational studies suggested that DHC provided a mortality benefit compared with medical management, for which mortality was 70-80\% $4,7-10,18,22,28,30,36,43,45,48$. However, authors called for an RCT to confirm the efficacy of surgical intervention. As many institutional studies reported that age negatively impacted patient outcomes ${ }^{7,10,18,22,36,48}$ the initial RCTs on DHC restricted the age of trial participants ${ }^{17,21,26,37,38}$. DECIMAL was a French multicenter, randomized trial involving 38 patients between 18-55 years of age $^{37}$. DESTINY enrolled 32 German patients aged 18-60 years ${ }^{26}$. HAMLET, the Dutch trial, included 64 patients aged 18-60 years ${ }^{21}$. The data were combined in a pooled analysis, and showed a $50 \%$ absolute risk reduction for mortality, further supporting survival benefit of DHC.

While mortality is often the primary outcome utilized in clinical trials, an individual's functional status is of equal if not more importance, particularly to the patient and caregivers. Quality outcomes are frequently measured with the modified Rankin Scale, (mRS; Table 1). The pooledanalysis of European RCTs showed improved quality outcomes with surgery: a $23 \%$ absolute risk reduction of $\mathrm{mRS}$ score $<3$, and a $51 \%$ absolute risk reduction of mRS score $<4^{37}$. Subgroup analysis of outcomes by age (dichotomized at 50) was underpowered ${ }^{38}$.

As evidence supporting DHC for stroke treatment increased, so did utilization ${ }^{1,6,42}$. A nationwide study of DHC use in America circa the European trials' publication noted a 3-fold increase in DHC between 1999 and 2008 ${ }^{42}$.
Nevertheless, the question of DHC appropriateness in patients aged greater than 60 years remained.

\section{Use of Decompressive Hemicraniectomy in Older Patients}

The understanding of DHC efficacy in older patients prior to recent RCTs was shaped by a combination of heterogeneous results from small institutional studies, which often lacked clear selection criteria and adequate representation of all age groups (Table 2) 4 ,7,8,10,18,22,24,30,34 ,36,48. A study in 1997 was one of the first to highlight agerelated differences in postoperative function ${ }^{7}$. Carter et al. reported five of five patients $<50$ years old with good postoperative mobility and self-care (Barthel Index scores $>60$ ), verses three of six older patients. In 2001, an institutional study of patients $>55$ years old showed that DHC decreased mortality, but all survivors had mRS scores $\geq 4^{22}$. In 2004, eight neurosurgical department databases were combined (188 patients) and showed that patients $>50$ years of age had significantly worse outcomes $(12.0 \%$ of older patients could function independently, versus $34.9 \%$ of younger individuals $)^{36}$. Importantly, many early institutional studies likely had unadjusted confounding from patient comorbidities, delayed surgery (intervention after $>48$ hours), or transtentorial herniation (clinical signs of decreased arousal, brainstem compression) $)^{23,25,35,39}$. Regardless, many authors recommended avoiding DHC in elderly patients unless a prospective randomized trial proved benefit.

The paucity of class I evidence on patients $>60$ years of age prompted additional trials to specifically analyze the utility of DHC among older adults ${ }^{16,27,35,49,50}$. In 2012, Zhao et al. published results of a prospective RCT for DHC versus conservative treatment enrolling 47 patients up to 80 years of age $\mathrm{e}^{50}$. In subgroup analysis of patients older than 60 , DHC decreased 6-month mortality more than conservative management $(12.5 \%$ versus $61.5 \%$, respectively). Regarding functional status, $31.2 \%(\mathrm{n}=16)$ of DHC patients experienced poor outcome ( $\mathrm{mRS}>4)$, versus $92.3 \%(\mathrm{n}=13)$ of individuals allocated to the medical treatment arm. However, interpretation of this data is limited by the small sample size and fact that $>60 \%$ of patients were from a single institution.

In 2014, the New England Journal of Medicine published

\begin{tabular}{|l|l|}
\hline mRS Score & Score Description \\
\hline 0 & No symptoms. \\
\hline 1 & No significant disability. Able to carry out all usual activities, despite some symptoms. \\
\hline 2 & Slight disability. Able to look after own affairs without assistance, but unable to carry out all previous activities. \\
\hline 3 & Moderate disability. Requires some help, but able to walk unassisted. \\
\hline 4 & Moderately severe disability. Unable to attend to own bodily needs without assistance, and unable to walk unassisted. \\
\hline 5 & Severe disability. Requires constant nursing care and attention, bedridden, incontinent. \\
\hline 6 & Dead \\
\hline
\end{tabular}

Table 1. Modified Rankin Scale (mRS). Scores are used to measure the degree of disability in patients who have had a stroke. 


\begin{tabular}{|c|c|c|c|c|}
\hline $\begin{array}{l}\text { First Author, } \\
\text { Publication Year, } \\
\text { Location }\end{array}$ & $\begin{array}{l}\text { Study Design } \\
\text { Setting }\end{array}$ & $\begin{array}{l}\text { Age Groups } \\
\text { (Years) }\end{array}$ & $\begin{array}{l}\text { Number of } \\
\text { Patients }\end{array}$ & Key Findings \\
\hline $\begin{array}{l}\text { Carter, } 1997 \\
\quad \text { USA }\end{array}$ & $\begin{array}{l}\text { Retrospective } \\
\text { Academic institution }\end{array}$ & $\begin{array}{l}<50 \\
\geq 50\end{array}$ & DHC 11 & $\begin{array}{l}\text { Of surviving patients, } 5 / 5 \text { patients }<50 \text { years old had good } \\
\text { postoperative mobility and self-care (BI scores }>60) \text {, verses } \\
3 / 6 \text { older patients. }\end{array}$ \\
\hline $\begin{array}{l}\text { Holtcamp, } 2001 \\
\text { Germany }\end{array}$ & $\begin{array}{c}\text { Retrospective } \\
\text { Academic institution }\end{array}$ & $>55$ & $\begin{array}{l}\text { DHC12 } \\
\text { Med } 12\end{array}$ & $\begin{array}{l}\text { Of DHC patients, } 8 / 12 \text { survived. None of the survivors had a } \\
\text { BI score above } 60 \text { or a } \mathrm{mRS}<4 \text {. }\end{array}$ \\
\hline $\begin{array}{l}\text { Walz, } 2002 \\
\text { Germany }\end{array}$ & $\begin{array}{l}\text { Retrospective } \\
\text { Academic institution }\end{array}$ & $\begin{array}{l}<45 \\
\geq 45\end{array}$ & DHC 18 & $\begin{array}{l}\text { Patients }<45 \text { years had a significantly better outcome than } \\
\text { patients } \geq 45 \text { by } \mathrm{BI} \text { scores and survival rates. }\end{array}$ \\
\hline $\begin{array}{l}\text { Gupta, } 2004 \\
\text { USA }\end{array}$ & Systematic review & $\begin{array}{l}<50 \\
\geq 50\end{array}$ & DHC 138 & $\begin{array}{l}\text { Of } 75 \text { patients who were }>50 \text { years of age, } 80 \% \text { were dead } \\
\text { or severely disabled compared with } 32 \% \text { of the } 63 \text { patients } \\
\leq 50 \text { years of age. }\end{array}$ \\
\hline $\begin{array}{l}\text { Uhl, } 2004 \\
\text { Germany }\end{array}$ & $\begin{array}{c}\text { Retrospective } \\
\text { Academic institutions }\end{array}$ & $\begin{array}{l}<50 \\
\geq 50\end{array}$ & DHC 188 & $\begin{array}{l}\text { Poor outcome (Glascow Outcome Score } \leq 3 \text { ) was } \\
\text { significantly associated with age }>50 \text { years. }\end{array}$ \\
\hline $\begin{array}{l}\text { Yao, } 2005 \\
\text { China }\end{array}$ & $\begin{array}{l}\text { Retrospective } \\
\text { Academic institution }\end{array}$ & $\begin{array}{l}<60 \\
\geq 60\end{array}$ & DHC 25 & $\begin{array}{l}\text { Mortality was } 7.7 \% \text { in younger patients (aged }<60 \text { years) } \\
\text { compared with } 33.3 \% \text { in elderly patients (aged } \geq 60 \text { years). } \\
\text { Younger patients also had higher BI scores and were more } \\
\text { likely to achieve } \mathrm{mRS} \leq 3 \text {. }\end{array}$ \\
\hline $\begin{array}{l}\text { Curry, } 2005 \\
\text { USA }\end{array}$ & $\begin{array}{l}\text { Retrospective } \\
\text { Academic institution }\end{array}$ & $\begin{array}{l}<40 \\
\geq 40\end{array}$ & DHC 38 & $\begin{array}{l}\text { BI score and ability to walk were strongly correlated with } \\
\text { age but not time to surgery, volume of infarction, or } \\
\text { craniectomy size. }\end{array}$ \\
\hline $\begin{array}{l}\text { Rabinstein, } 2006 \\
\text { USA }\end{array}$ & $\begin{array}{c}\text { Retrospective } \\
\text { Academic institutions }\end{array}$ & $\begin{array}{l}\text { Range } 15-73 \\
\text { Linear analysis }\end{array}$ & DHC 42 & $\begin{array}{l}\text { All but one of the patients with favorable recovery (mRS } \leq 3 \text { ) } \\
\text { were younger than } 55 \text { years. Older age was an independent } \\
\text { predictor of poor outcome (OR } 2.9 \text { [ } 95 \% \mathrm{Cl}: 1.04 \text { to } 8.07] \\
\text { per } 10 \text {-year increase in age. }\end{array}$ \\
\hline $\begin{array}{l}\text { Zhao, } 2012 \\
\text { China }\end{array}$ & $\begin{array}{c}\text { RCT } \\
\text { Multicenter trial }\end{array}$ & $\begin{array}{l}<60 \\
\geq 60\end{array}$ & $\begin{array}{l}\text { DHC } 24 \\
\text { Med } 23\end{array}$ & $\begin{array}{l}\text { For patients up to } 80 \text { years, DHC within } 48 \text { hours of stroke } \\
\text { onset increases survival and likelihood of good functional } \\
\text { outcome ( } m R S \leq 3 \text { ). }\end{array}$ \\
\hline $\begin{array}{l}\text { Tsai, } 2012 \\
\text { China }\end{array}$ & $\begin{array}{l}\text { Retrospective } \\
\text { Military Hospital }\end{array}$ & $\begin{array}{l}<60 \\
\geq 60\end{array}$ & $\begin{array}{l}\text { DHC } 37 \\
\text { Med } 42\end{array}$ & $\begin{array}{l}\text { DHC improved survival of all age groups. There was no } \\
\text { significant difference in functional outcome between } \\
\text { patients }<60 \text { versus } \geq 60 \text { years of age. }\end{array}$ \\
\hline $\begin{array}{l}\text { Yu, } 2012 \\
\text { Korea }\end{array}$ & $\begin{array}{c}\mathrm{RCT} \\
\text { Academic institution }\end{array}$ & $\begin{array}{l}<60 \\
\geq 60\end{array}$ & $\begin{array}{l}\text { DHC } 58 \\
\text { Med } 73\end{array}$ & $\begin{array}{l}\text { Age ( } \geq 70 \text { years vs. }<70 \text { years) did not statistically differ } \\
\text { between groups for the six-month mortality rate. }\end{array}$ \\
\hline $\begin{array}{c}\text { Inamasu, } 2013 \\
\text { Japan }\end{array}$ & $\begin{array}{c}\text { Retrospective } \\
\text { Academic institution }\end{array}$ & $\begin{array}{l}61-70 \\
>70\end{array}$ & DHC 18 & $\begin{array}{l}\text { 30-day mortality rate was significantly higher in the group } \\
\text { that was }>70 \text { years of age ( } 0 \% \text { vs } 60 \% \text { ) than in the group } \\
\text { that was } 61 \text { to } 70 \text { years of age. }\end{array}$ \\
\hline $\begin{array}{l}\text { Frank, } 2014 \\
\text { North America }\end{array}$ & $\begin{array}{l}\text { Randomized pilot study } \\
\text { Multicenter trial }\end{array}$ & $\begin{array}{l}\text { Range } 18-75 \\
\text { Linear analysis }\end{array}$ & $\begin{array}{l}\text { DHC } 14 \\
\text { Med } 10\end{array}$ & $\begin{array}{l}\text { HeADDFIRST: At } 6 \text { months, mortality rate for conservatively } \\
\text { treated patients was } 40 \% \text {; DHC, } 36 \% \text {. Authors attributed } \\
\text { relatively low mortality rate in conservative treatment group } \\
\text { (compared to European RCTs) to (1) older patients having } \\
\text { more brain atrophy and ability to tolerate cerebral edema } \\
\text { better than younger patients, and (2) strict adherence to a } \\
\text { standardized medical management protocol. }\end{array}$ \\
\hline $\begin{array}{l}\text { Juttler } 2014 \\
\text { Germany }\end{array}$ & $\begin{array}{c}\mathrm{RCT} \\
\text { Multicenter trial }\end{array}$ & $>60$ & $\begin{array}{l}\text { DHC } 56 \\
\text { Med } 56\end{array}$ & $\begin{array}{l}\text { DESTINY II: DHC improved outcomes compared to medical } \\
\text { management: survival without severe disability ( } 38 \% \text { vs } \\
18 \% \text {, respectively); mRS=4 ( } 32 \% \text { and } 15 \%) \text {; and } m R S=5 \\
\text { ( } 28 \% \text { and } 13 \%) \text {. }\end{array}$ \\
\hline $\begin{array}{l}\text { Suyama, } 2014 \\
\text { Japan }\end{array}$ & $\begin{array}{c}\text { Retrospective } \\
\text { Multicenter survey }\end{array}$ & $\begin{array}{l}<60 \\
\geq 60\end{array}$ & DHC 355 & $\begin{array}{l}\text { Of all DHC patients, } 80.2 \% \text { were } \geq 60 \text { years of age. Age was } \\
\text { not an independent predictor of mortality. At } 3 \text { months, } \\
\text { only } 5.2 \% \text { of patients had } \mathrm{mRS} \leq 3 \text {. }\end{array}$ \\
\hline $\begin{array}{l}\text { Lu, } 2015 \\
\text { China }\end{array}$ & Meta analysis & $\begin{array}{l}<60 \\
\geq 60\end{array}$ & DHC 747 & $\begin{array}{l}\text { DHC within } 48 \text { hours improved patient survival for all } \\
\text { age groups. The proportion of older patients with poor } \\
\text { functional outcome ( } 88.3 \%) \text { was significant higher than } \\
\text { that of younger patients }(66.8 \%) \text {. }\end{array}$ \\
\hline $\begin{array}{l}\text { Ragoschke- } \\
\text { Schumm, } 2015 \\
\text { Germany }\end{array}$ & $\begin{array}{c}\text { Prospective database and } \\
\text { interview, } \\
\text { Academic institution }\end{array}$ & $\begin{array}{l}<60 \\
\geq 60\end{array}$ & DHC 79 & $\begin{array}{l}\text { Despite impaired functional outcome after DHC, indicators } \\
\text { of quality of life and retrospective consent are higher for } \\
\text { patients older than } 60 \text { years over the long term. }\end{array}$ \\
\hline
\end{tabular}




\begin{tabular}{|c|c|c|c|c|}
\hline $\begin{array}{c}\text { van Middelaar, } \\
2015\end{array}$ & Systematic review & $\begin{array}{c}<6 \\
\text { Netherlands }\end{array}$ & DHC 459 & $\begin{array}{l}\text { Patients }<60 \text { years old had a better functional outcomes } \\
\text { (mRS } \leq 3) \text { and reported quality of life (surveys) in } \\
\text { comparison with older patients. }\end{array}$ \\
\hline $\begin{array}{c}\text { Dasenbrock, 2016 } \\
\text { USA }\end{array}$ & $\begin{array}{c}\text { Retrospective } \\
\text { Nationwide database }\end{array}$ & $\begin{array}{c}<60 \\
>70\end{array}$ & DHC 1673 & $\begin{array}{l}\text { DHC associated with reduced mortality in all age groups. } \\
\text { DHC patients }>60 \text { years experienced higher odds of } \\
\text { mortality (32.4\%) discharge to institutional care (47.1\%), } \\
\text { and a poor outcome (77.0\%) compared with younger } \\
\text { patients. }\end{array}$ \\
\hline $\begin{array}{c}\text { Fehnel 2016 } \\
\text { USA }\end{array}$ & $\begin{array}{c}\text { Retrospective } \\
\text { Nationwide database }\end{array}$ & $>65$ & DHC 130 & $\begin{array}{l}\text { There is a high rate of mortality among older stroke } \\
\text { patients undergoing DHC. Most survivors of DHC are not } \\
\text { permanently institutionalized (75\% home at 1 year) }\end{array}$ \\
\hline
\end{tabular}

BI: Barthel Index; DHC: decompressive hemicraniectomy; Med: medical treatment; mRS, modified Rankin Scale; RCT: randomized controlled trial.

Table 2. Summary of key studies evaluating DHC in older patient populations

DESTINY II, a German multicenter RCT investigating the efficacy of DHC in 112 patients $>60$ years of age ${ }^{27}$. The primary end point was survival without severe disability (mRS $\leq 4), 6$ months after randomization. In the DHC group, $38 \%$ survived without severe disability, compared to $18 \%$ in the control arm. The proportional differences between groups were dominated by mortality rates $(33 \%$ of surgical patients versus $70 \%$ medical). At 6 months, no patients had mRS scores $\leq 2 ; 7 \%$ of DHC patients and $3 \%$ of control patients had an $\mathrm{mRS}=3 ; 32 \%$ and $15 \%$, respectively, had scores of 4 ; and $28 \%$ and $13 \%, \mathrm{mRS}=5$. When comparing 12 month data to the original DESTINY trial of patients $\leq 60$ years of age, only $6 \%$ of older DHC patients had an mRS score $<4$, compared to $43 \%$ of younger counterparts. Therefore, DHC in older patients reduced mortality, but did not provide substantial gain in functional outcomes.

A subsequent meta-analysis assessing 14 studies and 747 patients greater or less than 60 years of age found that while all ages benefited from early intervention (DHC within 48 hours of stroke onset), older age was an important predictor of unfavorable outcome ${ }^{28}$. Patients $>60$ years of age had an $88.3 \%$ odds of $\mathrm{mRS}>3$, which was significantly higher than younger patients (66.8\%).

While RCTs provide the most internally valid form of clinical evidence for treatment efficacy, the effectiveness, or generalizability of such data to the clinical setting may be variable. Nationwide population studies offer alternative means to elucidate the degree to which RCT findings are congruent with daily practice. In our recent nationwide database analysis, we used the Nationwide Inpatient Sample, the largest all-payer inpatient health care database in the US, to determine how age impacted DHC-related morbidity and mortality ${ }^{11}$. The study included 1,673 patients with space-occupying cerebral infarction from hospitals in almost every American state. The large sample size, $37.6 \%>60$ years of age, allowed us to account for confounding factors, including individual comorbidities, stroke risk factors, treatment variables, and the timing of intervention in multivariable regression analyses. We reported survival benefit of DHC compared to medical treatment in all age groups, including those $>70$ years. However, patients $>60$ years had higher odds of postoperative mortality compared with younger patients (aged 18-50 years: 19\%, 51-60 years: $22.8 \%, 61-70$ years: $30.7 \%$, >70 years: $34.5 \%$ ). As mRS scores were not coded in the database, the variables of mortality, discharge to an institutional care facility, and tracheostomy or gastrostomy placement served as proxies for mRS score and were designated as a "poor outcome" 44 . Patients aged $>60$ years had increased odds of discharge to institutional care (47.1\%), and overall poor outcome (77.0\%).

Another nationwide study using the Medicare claims database, a federally funded health insurance program for patients $>65$ years of age in the United States, examined older patients' postoperative outcomes and use of longterm care facilities, as a proxy for independence ${ }^{13}$. Within 30 days of surgery, $38 \%$ of patients died, and $25 \%$ of survivors required acute hospital readmission. At one year, $55 \%$ of patients were deceased, and $29 \%$ of survivors required full-time care at a long-term care facility. This lies in contrast to the patients $>60$ years of age in the DESTINY II trial where, at one year, mortality was $43 \%$ and $57 \%$ of survivors required significant assistance (mRS 4-5) ${ }^{27}$.

In summary, while there is a general consensus from RCT, institutional, and nationwide data that DHC in patients $>60$ years of age decreases the odds of mortality compared to medical management, there remains a significant risk of morbidity for survivors. The aforementioned studies note that between $25 \%$ and $62 \%$ of patients will be left with moderately severe disability following DHC (mRS $>3$ ), and may be unable to perform activities of daily living unassisted.

\section{Perspective on Quality of Life}

Numerous studies in the past decade have proven that DHC in older patients is lifesaving, however, the risk of survival with moderate or severe disability fuels the ongoing debate about what should be considered an acceptable outcome for these patients ${ }^{4,5,14,15,33}$. Importantly, the perspective on the acceptability of survival with 
substantial disability can vary between clinicians, patients, and caregivers. In a recent multicenter, international, cross-sectional survey among 1,860 physicians who care for stroke patients, mRS scores $\leq 3$ were considered acceptable by the majority (79.3\%), while less than half $(38.0 \%)$ considered $\mathrm{mRS}=4$ to be an acceptable outcome ${ }^{29}$. However, the patient experience of stroke recovery may be better captured by quality of life (QoL) measures ${ }^{15,40,46}$. QoL is traditionally measured by Short-Form Health Survey (SF-36), Hamilton Depression Rating Scale (HDRS), Stroke Impact Scale (SIS), and European QoL Scale (EQ-5D). In DESTINY II, patients who underwent DHC had higher QoL scores than those treated conservatively (via SF-36, HDRS, and EQ-5D).

As QoL data are not routinely collected as primary outcomes in RCTs, Ali et al. examined the correlation of patients' perspectives on QoL with traditional functional outcome measures: mRS score, National Institutes of Health Stroke Scale, and Barthel Index ${ }^{3}$. QoL was assessed with the SIS and EQ-5D. The mRS aligned most with stroke survivors' interests, capturing more information on QoL than either the National Institutes of Health Stroke Scale or Barthel Index.

Retrospective consent is another approach to understanding patients' and caregivers' view on the value of DHC despite the likelihood for functional deficit; that is, knowing the outcome, would they still chose to have the operation. In DESTINY II, 63\% of surviving patients in the DHC group gave retrospective consent to treatment compared to $53 \%$ of those in the control group. Though, authors cautioned interpretation of these results, as 25 of 42 survivors were unable to answer due to severe aphasia or neuropsychological deficits ${ }^{27}$. An institutional study in Germany assessed 79 consecutive patients who underwent DHC for functional and psychological outcomes, as well as QoL and retrospective consent for the procedure ${ }^{31}$. Despite patients $>60$ years having worse functional outcomes after DHC, indicators of QoL and retrospective consent were higher than younger individuals. Of patients $<60$ years of age, $63 \%$ reported retrospective consent for DHC $(29 \%$ declined), older patients reported $82 \%$ consent, and none declined. Older patients also reported higher scores for all items on the SF-36 questionnaire, with the exception of 'General health', and the use of antidepressants was significantly lower in the older group: 9 vs. $58 \%$ in younger patients $^{31}$.

The aforementioned discrepancy between an individual's report of a high QoL, despite serious disability that most external observers would view as a poor QoL, is termed the "disability paradox"2. In these situations, patient reported QoL measures are less dependent on physical ability, and are more reflective of one's ability to sustain positive social relationships and engage in the external environment. Long-term consequences and QoL of both patients and their partners continue to be a point of investigation. The ongoing Restore4Stroke study is working to elucidate how QoL is impacted by health condition (prestroke and stroke-related health conditions), personal factors (coping and illness cognitions), and environmental factors (caregiver burden and social support) ${ }^{41}$. Overall, QoL measures and the prevalence of patients who retrospectively consent to $\mathrm{DHC}$ despite functional outcomes should be considered during counseling of patients and caregivers on postoperative expectations.

\section{Conclusion}

While the utility of DHC in patients with malignant cerebral edema has been shown in patients $<60$ years of age, the role of surgery in older patients is more complex. Recent clinical trials, institutional studies, and population analyses suggest that surgical decompression in older patients is lifesaving, but often results in survival with moderate or severe disability. What constitutes an acceptable outcome for these patients is controversial, and expectations for post-operative quality of life should be thoroughly communicated to patients and caregivers before surgery, and shared decision-making with this information should occur when possible. This literature review underscores the inherent complexity in balancing scientific evidence, clinical expertise and patient preference when considering hemicraniectomy for space-occupying infarction in older adults.

\section{References}

1. Adeoye $\mathrm{O}$, Hornung $\mathrm{R}$, Khatri $\mathrm{P}$, et al. The rate of hemicraniectomy for acute ischemic stroke is increasing in the United States. J Stroke Cerebrovasc Dis. 2011; 20: 251-254.

2. Albrecht GL, Devlieger PJ. The disability paradox: high quality of life against all odds. Soc Sci Med. 1999; 48: 977-988.

3. Ali M, Fulton R, Quinn T, et al. How well do standard stroke outcome measures reflect quality of life? A retrospective analysis of clinical trial data. Stroke. 2013; 44: 3161-3165.

4. Arac A, Blanchard V, Lee $\mathrm{M}$, et al. Assessment of outcome following decompressive craniectomy for malignant middle cerebral artery infarction in patients older than 60 years of age. Neurosurg Focus. 2009; 26: E3.

5. Back L, Nagaraja V, Kapur A, et al. Role of decompressive hemicraniectomy in extensive middle cerebral artery strokes: a metaanalysis of randomised trials. Intern Med J. 2015; 45: 711-717.

6. Bhattacharya P, Kansara A, Chaturvedi S, et al. What drives the increasing utilisation of hemicraniectomy in acute ischaemic stroke. J Neurol Neurosurg Psychiatry. 2013; 84: 727-731.

7. Carter BS, Ogilvy Cs Fau - Candia GJ, Candia Gj Fau - Rosas HD, et al. One-year outcome after decompressive surgery for massive nondominant hemispheric infarction. Neurosurgery. 1997; 01480396X (Print).

8. Chen CC, Cho DY, Tsai SC. Outcome of and prognostic factors for decompressive hemicraniectomy in malignant middle cerebral artery infarction. J Clin Neurosci. 2007; 14: 317-321.

9. Cheung A, Telaghani CK, Wang J, et al. Neurological recovery after 
decompressive craniectomy for massive ischemic stroke. Neurocrit Care. 2005; 3: 216-223.

10. Curry WT, Ogilvy CS, Carter BS, et al. Factors associated with outcome after hemicraniectomy for large middle cerebral artery territory infarction. Neurosurgery. 2005; 56: 681-692 discussion 681-692.

11. Dasenbrock HH, Robertson FC, Aziz-Sultan MA, et al. Patient Age and the Outcomes after Decompressive Hemicraniectomy for Stroke A Nationwide Inpatient Sample Analysis. Neurocrit Care. 2016.

12. DuGoff EH, Canudas-Romo V, Buttorff C, et al. Multiple chronic conditions and life expectancy a life table analysis. Med Care. 2014; 52: 688-694.

13. Fehnel CR, Lee Y, Wendell LC, et al. Utilization of long-term care after decompressive hemicraniectomy for severe stroke among older patients. Aging Clin Exp Res. 2016.

14. Flechsenhar J, Woitzik J, Zweckberger K, et al. Hemicraniectomy in the management of space-occupying ischemic stroke. J Clin Neurosci. 2013; 20: 6-12.

15. Foerch C, Lang JM, Krause J, et al. Functional impairment disability, and quality of life outcome after decompressive hemicraniectomy in malignant middle cerebral artery infarction. J Neurosurg. 2004; 101: 248-254.

16. Frank JI, Schumm LP, Wroblewski K, et al. Hemicraniectomy and durotomy upon deterioration from infarction-related swelling trial randomized pilot clinical trial. Stroke. 2014; 45: 781-787.

17. Geurts M, van der Worp Hb Fau - Kappelle LJ, Kappelle Lj Fau Amelink GJ, et al. Surgical decompression for space-occupying cerebral infarction outcomes at 3 years in the randomized HAMLET trial. Stroke. 2013

18. Gupta R, Connolly ES, Mayer S, et al. Hemicraniectomy for massive middle cerebral artery territory infarction a systematic review. Stroke. 2004; 35: 539-543.

19. Hacke W, Schwab S, Horn M, et al. 'Malignant' middle cerebral artery territory infarction: clinical course and prognostic signs. Arch Neurol. 1996; 53: 309-315.

20. Hobson RW, Howard VJ, Roubin GS, et al. Carotid artery stenting is associated with increased complications in octogenarians 30-day stroke and death rates in the CREST lead-in phase. J Vasc Surg. 2004; 40: 1106-1111.

21. Hofmeijer J, Kappelle LJ, Algra A, et al. Surgical decompression for space-occupying cerebral infarction the Hemicraniectomy After Middle Cerebral Artery infarction with Life-threatening Edema Trial HAMLET a multicentre open randomised trial. The Lancet Neurology. 2009; 8: 326-333.

22. Holtkamp M, Buchheim K, Unterberg A, et al. Hemicraniectomy in elderly patients with space occupying media infarction improved survival but poor functional outcome. J Neurol Neurosurg Psychiatry. 2001; 70: 226-228.

23. Huttner HB, Schwab S. Malignant middle cerebral artery infarction clinical characteristics, treatment strategies and future perspectives. Lancet Neurol. 2009; 8: 949-958.

24. Inamasu J, Kaito T, Watabe T, et al. Decompressive hemicraniectomy for malignant hemispheric stroke in the elderly comparison of outcomes between individuals $61-70$ and $>70$ years of age. J Stroke Cerebrovasc Dis. 2013; 22: 1350-1354.

25. Juttler E, Hacke W. Early decompressive hemicraniectomy in older patients with nondominant hemispheric infarction improves outcome. Stroke. 2011; 42: 843-844.

26. Juttler E, S S, P S, et al Decompressive Surgery for the Treatment of Malignant Infarction of the Middle Cerebral Artery (DESTINY) a randomized, controlled trial. Stroke. 2007.

27. Juttler E, Unterberg A, Woitzik J, et al. Hemicraniectomy in older patients with extensive middle-cerebral-artery stroke. N Engl J Med. 2014; 370: 1091-1100.

28. Lu X, Huang B, Zheng J, et al. Decompressive craniectomy for the treatment of malignant infarction of the middle cerebral artery. Sci Rep. 2014; 4: 7070.

29. Neugebauer H, Creutzfeldt CJ, Hemphill JC, et al. DESTINY-S attitudes of physicians toward disability and treatment in malignant MCA infarction. Neurocrit Care. 2014; 21: 27-34.

30. Rabinstein AA, Mueller-Kronast N, Maramattom BV, et al. Factors predicting prognosis after decompressive hemicraniectomy for hemispheric infarction. Neurology. 2006; 67: 891-893.

31. Ragoschke-Schumm A, Junk C, Lesmeister M, et al. Retrospective Consent to Hemicraniectomy after Malignant Stroke among the Elderly, Despite Impaired Functional Outcome. Cerebrovasc Dis. 2015; 40: 286-292.

32. Rieke K, Schwab S, Krieger D, et al. Decompressive surgery in spaceoccupying hemispheric infarction results of an open prospective trial. Crit Care Med. 1995; 23: 1576-1587.

33. Schirmer CM, Ackil AA, Malek AM. Decompressive Craniectomy. Neurocrit Care. 2008; 8: 456-470.

34. Suyama K, Horie N, Hayashi K, et al. Nationwide survey of decompressive hemicraniectomy for malignant middle cerebral artery infarction in Japan. World Neurosurg. 2014; 82: 1158-1163.

35. Tsai CL, Chu H, Peng GS, et al. Preoperative APACHE II and GCS scores as predictors of outcomes in patients with malignant MCA infarction after decompressive hemicraniectomy. Neurol India. 2012; 60: 608612.

36. Uhl E, Kreth FW, Elias B, et al. Outcome and prognostic factors of hemicraniectomy for space occupying cerebral infarction. J Neurol Neurosurg Psychiatry. 2004; 75: 270-274.

37. Vahedi K, E V, J M, et al. Sequential-design multicenter randomized controlled trial of early decompressive craniectomy in malignant middle cerebral artery infarction (DECIMAL Trial). Stroke. 2007; 1524-4628 (Electronic).

38. Vahedi K, Hofmeijer J, Juettler E, et al. Early decompressive surgery in malignant infarction of the middle cerebral artery a pooled analysis of three randomised controlled trials. Lancet Neurol. 2007; 6: 215-222.

39. van der Worp HB, Kappelle LJ. Early decompressive hemicraniectomy in older patients with nondominant hemispheric infarction does not improve outcome. Stroke. 2011; 42: 845-846.

40. van Middelaar T, Nederkoorn PJ, van der Worp HB, et al. Quality of life after surgical decompression for space-occupying middle cerebral artery infarction systematic review. Int J Stroke. 2015; 10: 170-176.

41. van Mierlo ML, van Heugten CM, Post MW, et al. A longitudinal cohort study on quality of life in stroke patients and their partners Restore4Stroke Cohort. Int J Stroke. 2014; 9: 148-154.

42. Walcott BP, Kuklina EV, Nahed BV, et al. Craniectomy for malignant cerebral infarction: prevalence and outcomes in US hospitals. PLoS One. 2011; 6: e29193.

43. Walz B, Zimmermann C, Bottger S, et al. Prognosis of patients after hemicraniectomy in malignant middle cerebral artery infarction. J Neurol. 2002; 249: 1183-1190.

44. Washington CW, Derdeyn CP, Dacey RG, et al. Analysis of subarachnoid hemorrhage using the Nationwide Inpatient Sample the NIS-SAH Severity Score and Outcome Measure. J Neurosurg. 2014; 121: 482-489.

45. Wijdicks EF, Sheth KN, Carter BS, et al. Recommendations for the management of cerebral and cerebellar infarction with swelling a statement for healthcare professionals from the American Heart Association/American Stroke Association. Stroke. 2014; 45: 1222-1238. 
46. Woertgen C, Erban P, Rothoerl RD, et al. Quality of life after decompressive craniectomy in patients suffering from supratentorial brain ischemia. Acta Neurochir (Wien). 2004; 146: 691-695.

47. Wolf PA, D'Agostino RB, O'Neal MA, et al. Secular trends in stroke incidence and mortality The Framingham Study. Stroke. 1992; 23: 1551-1555.

48. Yao Y, Liu W, Yang X, et al. Is decompressive craniectomy for malignant middle cerebral artery territory infarction of any benefit for elderly patients. Surg Neurol. 2005; 64: 165-169 discussion 169.
49. Yu JW, Choi JH, Kim DH, et al. Outcome following decompressive craniectomy for malignant middle cerebral artery infarction in patients older than 70 years old. J Cerebrovasc Endovasc Neurosurg. 2012; $14: 65-74$.

50. Zhao J, Su YY, Zhang Y, et al. Decompressive hemicraniectomy in malignant middle cerebral artery infarct a randomized controlled trial enrolling patients up to 80 years old. Neurocrit Care. 2012; 17: 161-171. 